\title{
A modified method for consistent and reliable Golgi-Cox staining in significantly reduced time
}

\section{Amit Ranjan and Birendra Nath Mallick* \\ School of Life Sciences, Jawaharlal Nehru University, New Delhi, India}

\section{Edited by:}

René Drucker-Colin, Universidad

Nacional Autónoma de México, Mexico

\section{Reviewed by:}

Raul Aguilar-Roblero, Universidad

Nacional Autónoma de México, Mexico

Joaquin Reyes Tellez Giron, Universidad

Nacional Autonoma de Mexico, Mexico

*Correspondence:

Birendra Nath Mallick, School of Life

Sciences, Jawaharlal Nehru University,

New Delhi, India.

e-mail: remsbnm@yahoo.com
The two major limitations of Golgi-Cox method are that staining takes very long time and it is inconsistent. In this paper we describe a modification of the Golgi-Cox method, in which the tissue blocks were maintained at $37 \pm 1^{\circ} \mathrm{C}$ during chromation for only $24 \mathrm{~h}$ and consistent staining of neurons in rat brain sections were observed. The method is simple, reproducible, rapid, inexpensive, and provides uniform staining with very good resolution of neuronal soma, dendrites as well as spines.

Keywords: Golgi-Cox stain, incubation temperature, normal body temperature, reduced incubation period, thick section, thick tissue block

\section{INTRODUCTION}

The classical Golgi method for staining neurons in the brain was first developed by Camillio Golgi (Golgi, 1873 in Mazzarello, 1999). Subsequently, the great neuroanatomist Ramon y Cajal (1909) applied the technique to demonstrate previously unimagined neuronal morphology virtually in all parts of the nervous system. However, the main drawback of the method is inconsistency of impregnation of the stain into the neurons resulting in reduced specificity, reproducibility, and success rate (Globus and Scheibel, 1966; Pasternak and Woolsey, 1975; Zhang et al., 2003). Several modifications of the method have been tried which include variations in pH (Bertram and Ihrig, 1957; Gonzalez-Burgos et al., 1992; Angulo et al., 1994), application of vacuum (Friedland et al., 2006), coating of brain blocks with egg yolk (Zhang et al., 2003), use of microwaves (Armstrong and Parker, 1986; Marani et al., 1987; Zhang et al., 2003) and variations in temperature of the tissue incubating medium (Armstrong and Parker, 1986; Berbel, 1986; Marani et al., 1987; Angulo et al., 1994). These modifications were aimed at faster staining process by decreasing the time for staining, reducing precipitation, promoting uniform crystallization, increasing reliability, and reproducibility of staining neurons by the Golgi method.

The Golgi-Cox method has been frequently used to stain neurons in both less myelinated, younger as well as in more myelinated, older rat brains. As compared to Golgi method the advantage of Golgi-Cox method include increased probability of staining more number of neurons (Scheibel and Tomiyasu, 1978); it is also reported to be better than the rapid Golgi method for studying neuronal dendritic morphology (Buell, 1982). However, the duration of impregnation of stain using Golgi-Cox method has been reported to be between 14 and 80 days (Rutledge et al., 1969; Glaser and Van der Loos, 1981; Zhang et al., 2003), depending on whether whole brain or smaller blocks of brain were used for staining, i.e., primarily depending on the thickness of the tissue block (sample). Thus, apart from inconsistency and lack of uniform, reproducible results, requirement of exceptionally long time to achieve neuronal staining is another major disadvantage of both the Golgi and Golgi-Cox methods, which practically limits the use of these methods.

One of the possibilities to overcome the shortcomings of the Golgi-Cox method mentioned above could be by increasing random motion of the metallic ions in the staining solution facilitating their influx and deposition within the neurons; thus reducing the time required as well as increasing the success rate of more stained neurons and reproducibility of results. Here we describe a simple and inexpensive modification where we raised the temperature of the Golgi-Cox solution in which moderately thick slices of brain were incubated only for $24 \mathrm{~h}$ and that gave us significantly more impregnation of stain and consistently excellent results in terms of stained neurons.

\section{MATERIALS AND METHODS}

Experiments were conducted on inbred male wistar rats (250$300 \mathrm{~g}$ ) maintained in their standard home cages under 12:12 h light/dark cycle with food and water ad libitum. The experiments were approved by the Institutional Animal Ethics Committee (IAEC) and every effort was made to minimize the use of number of animals and their sufferings. Four rats were deeply anesthetized with over dose of ketamine-xylazine (80-32 mg/kg, i.p.) (Chandra Bhagat Pharma Pvt Ltd, India) and then intracardially perfused with $0.1 \mathrm{M}$ phosphate buffered saline (PBS, pH 7.4). For comparison and to differentiate if blood and perfusion play any role in staining, another four rats were sacrificed by cervical dislocation followed by decapitation. All the brains were removed, washed with distilled water followed by with freshly prepared Golgi-Cox solution (Rutledge et al., 1969). The brains were placed in a 1-mm brain slicer (WPI, USA) and three $5 \mathrm{~mm}$ thick coronal blocks A, B, and C were prepared (Figure 1). Each of those coronal blocks was further cut into two equal mirror halves by giving a longitudinal cut along the midline. Thus, a total of six blocks labeled as A1, A2, B1, B2, C1, and C2 were obtained (Figure 1). 


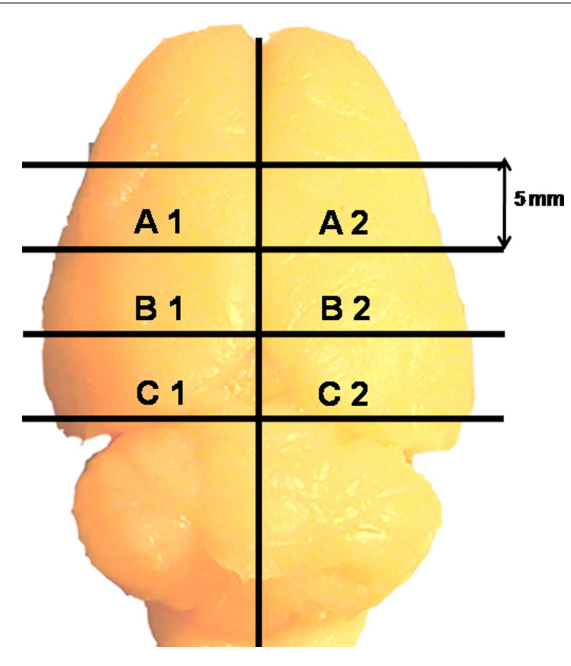

FIGURE 1 | A rat brain showing how four coronal and one sagittal cuts were given to obtain six blocks from each rat brain.

Each tissue block was placed in separate cotton lined dark colored glass bottle containing 25-30 ml freshly prepared GolgiCox solution. Bottles containing blocks A1, B1, and C1 were maintained in an incubator at $37 \pm 1^{\circ} \mathrm{C}$ for 6,12 , and $24 \mathrm{~h}$, respectively, while bottles containing blocks A2, B2, and C2 were incubated at $26 \pm 1^{\circ} \mathrm{C}$ for 6,12 , and $24 \mathrm{~h}$, respectively. Thus, all other conditions, except temperature, were identical in the two groups; hence the groups served as control for each other. At each time point one block (say A1) from $37^{\circ} \mathrm{C}$ and the corresponding contralateral block (in this case A2) from $26^{\circ} \mathrm{C}$ were taken and processed simultaneously; blocks B1, C1 and B2, C2 were processed similarly. This strategy ensured comparisons between sections from comparable brain areas from the same animal treated under identical conditions except that of change in the incubation temperature. As it will be seen later, since the results of intracardial perfused brain samples and that of brains taken out without intracardial perfusion were comparable after $24 \mathrm{~h}$ incubation, only the latter samples were treated for 6 and $12 \mathrm{~h}$. We treated the three separate blocks of tissues for 6, 12, and $24 \mathrm{~h}$ in the Golgi-Cox solution and four such repetitions were conducted.

Further, to confirm if the temperature was affecting primarily the permeability of the stain resulting in increased staining efficiency, we kept separate brain blocks in Golgi-Cox solution containing sodium dodecyl sulfate (SDS) or Triton X-100. In separate sets, brain blocks as mentioned above were incubated at $37 \pm 1$ and $26 \pm 1^{\circ} \mathrm{C}$ in Golgi-Cox solution containing either 0.1 or $0.2 \%$ SDS or $0.5 \%$ Triton X-100 (Table 1). Since the results of perfused brain after $24 \mathrm{~h}$ incubation in Golgi-Cox solution were similar (Figure 2) to those of non-perfused brain, rest all the studies were conducted on the latter only.

\section{SAMPLE PREPARATION}

At the end of incubation of the brain tissue in the staining solution for varying period, $200 \mu \mathrm{m}$ thick sections were prepared from each of the treated and control blocks using a vibratome (3000 series, Evergreen Blvd-St. Louis, MO, USA; Gibb and Kolb, 1998). It may
Table 1 | Completely filled neurons in $200 \mu \mathrm{m}$ thick sections prepared from $5 \mathrm{~mm}$ brain blocks treated under various conditions.

\begin{tabular}{|c|c|c|}
\hline \multirow{2}{*}{$\begin{array}{l}\text { Incubation conditions of } \\
\text { brain tissue blocks }\end{array}$} & \multicolumn{2}{|c|}{ Incubation for $24 \mathrm{~h}$ at } \\
\hline & $37 \pm 1^{\circ} \mathrm{C}$ & $26 \pm 1{ }^{\circ} \mathrm{C}$ \\
\hline $0.2 \%$ SDS in Golgi-Cox solution & $+H$ & - \\
\hline $0.1 \%$ SDS in Golgi-Cox solution & $+1+$ & - \\
\hline $0.5 \%$ triton-X in Golgi-Cox solution & $+1+$ & - \\
\hline Golgi-Cox solution only & $+1+$ & - \\
\hline
\end{tabular}

+++ Indicates completely filled neurons in cortical and sub-cortical regions, - denotes some nucleation centers and very few partially filled cell bodies scattered in some cortical areas.

also be noted that in pilot studies uneven hand cut $(90-350 \mu \mathrm{m})$ sections also gave us comparable staining. The, sections were processed as follows:

1. Rinsed twice ( $5 \mathrm{~min}$ each) in distilled water to remove traces of impregnating solution.

2. Dehydrated in $50 \%$ alcohol for $5 \mathrm{~min}$.

3. Kept in ammonia solution (3:1, ammonia:distilled water) for 5-10 min.

4. Rinsed twice ( 5 min each) in distilled water.

5. Kept in 5\% sodium thiosulfate for $10 \mathrm{~min}$ in dark.

6. Rinsed twice for $2 \mathrm{~min}$ each in distilled water.

7. Dehydrated twice (5-10 min each) in 70, 80, 95\% ethanol and 99\% 1-butanol, cleared in toluene and mounted in DPX on gelatinized slides.

The slides were allowed to dry at room temperature and were observed under a microscope (Nikon Eclipse E400, Japan and Olympus BX51, Japan) at low and high magnifications. Images were captured using a charged coupled device (CCD) digital camera (JVC, Tokyo, Japan and MBF CX9000) attached to the microscope using dedicated software Image-Pro Plus 5.1.1 (Media Cybernetics, Silver Spring, USA) and/or Neurolucida 9 (MBF Biosciences, USA).

The intensity of black staining of neurons in the sections was visually compared under microscope. In our pilot studies no nucleation of black stain was observed until $4 \mathrm{~h}$ incubation; however, significant number of completely filled neurons was seen after $24 \mathrm{~h}$ of incubation at $37^{\circ} \mathrm{C}$. Hence, in this study we chose to incubate the brain slices at $37^{\circ} \mathrm{C}$ and $26^{\circ} \mathrm{C}$ for 6,12 and $24 \mathrm{~h}$ in the staining solution. The following criteria were adopted for identification of staining for evaluation.

i) Staining was considered to have been initiated if visible black spot (nucleation) could be distinctly identified inside the neurons without spilling over to the surrounding; the latter (not many though) was considered due to neuronal damage or non-specific artifact.

ii) Neurons were considered completely stained if the soma, axons, and dendrites could be seen well demarcated by the impregnated black stain without spilling outside the neurons. 


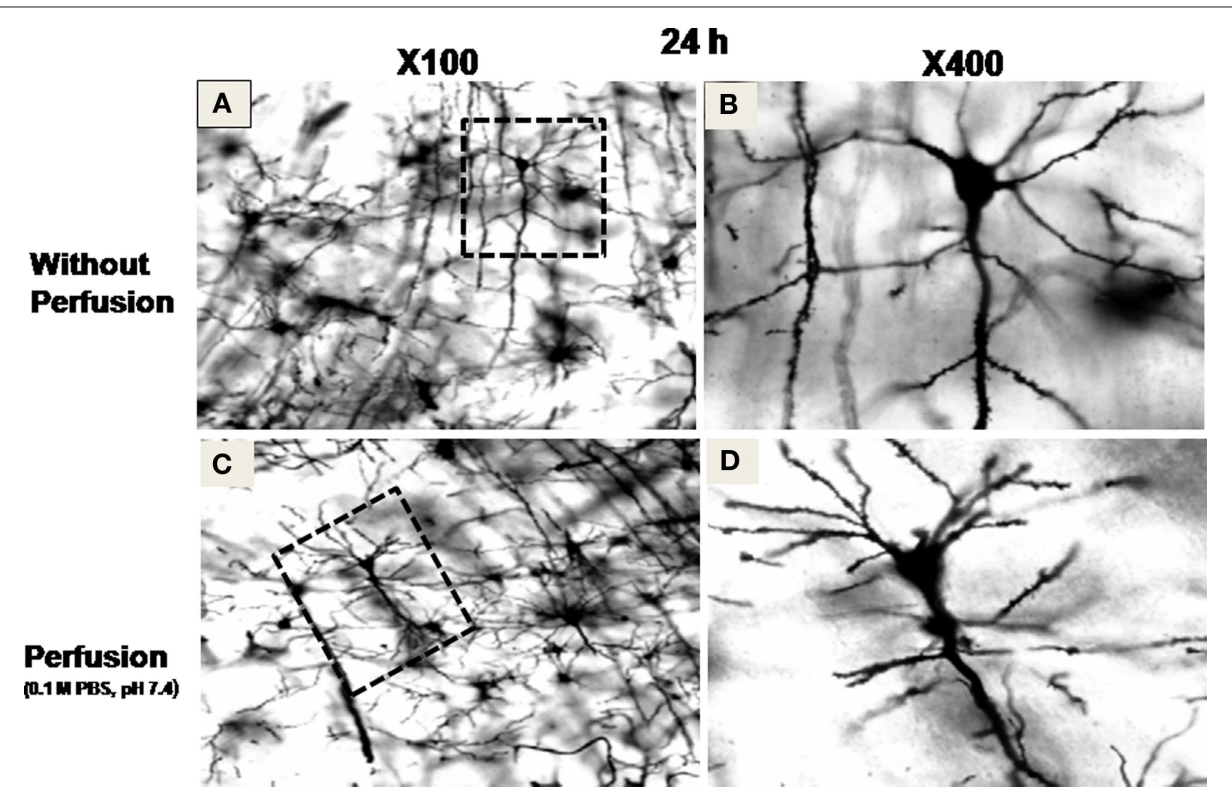

FIGURE 2 | Stained neurons in sections prepared from brain blocks incubated at $\mathbf{3 7} \pm \mathbf{1}^{\circ} \mathbf{C}$ for $\mathbf{2 4} \mathbf{h}$. Sections (A) and (B) were prepared without perfusion of the brain, while sections $(\mathbf{C})$ and $(\mathbf{D})$ were prepared after intracardial perfusion of the brain with $0.1 \mathrm{M}$ phosphate buffered saline $(\mathrm{PBS})$ at $\mathrm{pH} 7.4$. (A) and $(\mathbf{C})$ at $\times 100$ magnification, while (B) and (D) at $\times 400$ magnification of the area marked on $(\mathbf{A})$ and $(\mathbf{C})$, respectively, showing completely filled neurons.

For quantitative estimation, five to six sections from each category $\left(6,12,24 \mathrm{~h}\right.$ in 26 and $\left.37^{\circ} \mathrm{C}\right)$ were observed under microscope $(\times 100$ magnification). Every section was divided into two equal zones from the center; outer one was considered cortical while adjacent inner part was considered as sub-cortical (Figure 3). In each section four to six frames (Figure 3) were taken at random from cortical and sub-cortical regions $(640 \times 480$ pixels or $220 \times 170 \mu \mathrm{m})$ using CCD camera (JVC, Japan) attached to the microscope (Nikon Eclipse E400). On an average about $26 \pm 2$ images were taken from sections of each category. We counted the stained neurons under various conditions as defined above using dedicated software ImagePro Plus 5.1.1 (Media Cybernetics, Silver Spring, USA). Stereoscopic view of sample neurons was also observed by tracing soma, dendrites, and axons in 3-Dimension (3-D) using Neurolucida software (MBF Biosciences, USA). The neurons were viewed in different planes and were captured using a digital camera (MBF CX9000) attached to the microscope (Olympus BX51, Japan). Dedicated software Neurolucida 9 and Neurolucida Explorer (MBF Biosciences, USA) were used to reconstruct 3-D view (X1000) of the neurons from the captured pictures, which may be conveniently used for qualitative and quantitative analysis.

\section{RESULTS}

Early sign of nucleation (filling of neurons with black products) started appearing after $6 \mathrm{~h}$ of incubation of the blocks at $37 \pm 1^{\circ} \mathrm{C}$, while no such sign was visible in the sections prepared from blocks incubated at $26 \pm 1^{\circ} \mathrm{C}$ (Figure 4).

By $12 \mathrm{~h}$ of incubation at $37 \pm 1^{\circ} \mathrm{C}$ although many significantly filled (black) neurons could be seen in the cortical region of the sections; in very few sections partially filled neurons could be occasionally seen in the sub-cortical regions only. After $24 \mathrm{~h}$ of incubation almost all the stained neurons were completely impregnated

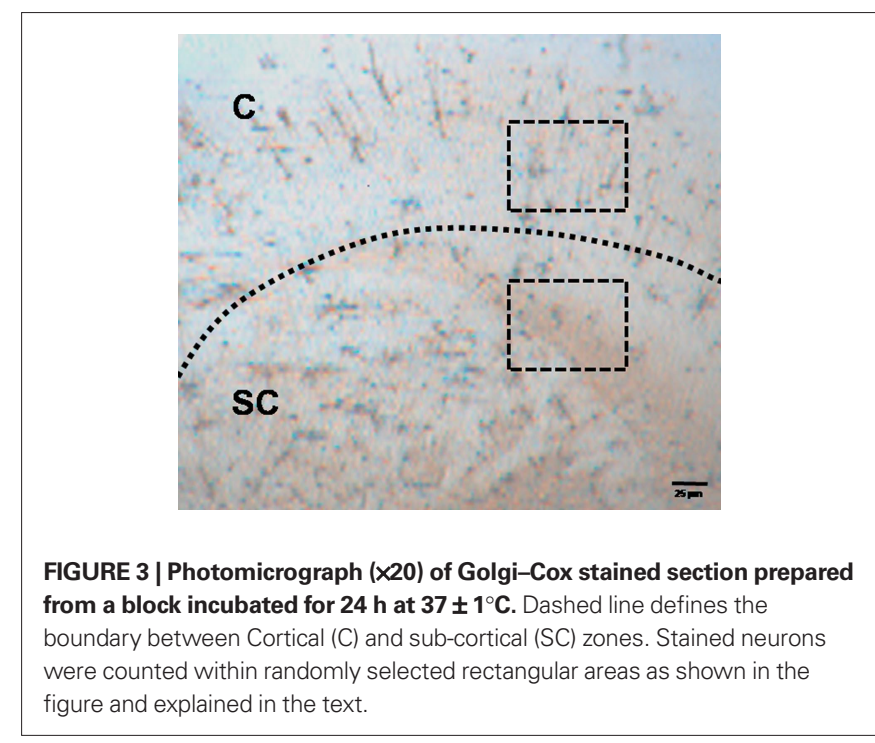

with black stain in both the cortical and the sub-cortical regions of the sections prepared from tissue blocks incubated at $37 \pm 1^{\circ} \mathrm{C}$. However, the number of completely filled neurons in the subcortical region was significantly lesser than those in the cortical region (Figures 4-6). Under higher magnification $(\times 1000)$, nice and clear dendritic spines could be seen against a clear background in sections obtained from the blocks incubated at $37 \pm 1^{\circ} \mathrm{C}$ for $24 \mathrm{~h}$ (Figure 6). Such results from blocks incubated at $37 \pm 1^{\circ} \mathrm{C}$ were uniformly distributed throughout the sections and were consistent in all the sets of experiments irrespective of intracardial perfusion or not. Detail morphology of stained neurons in 3-D is shown in Figure 7. 


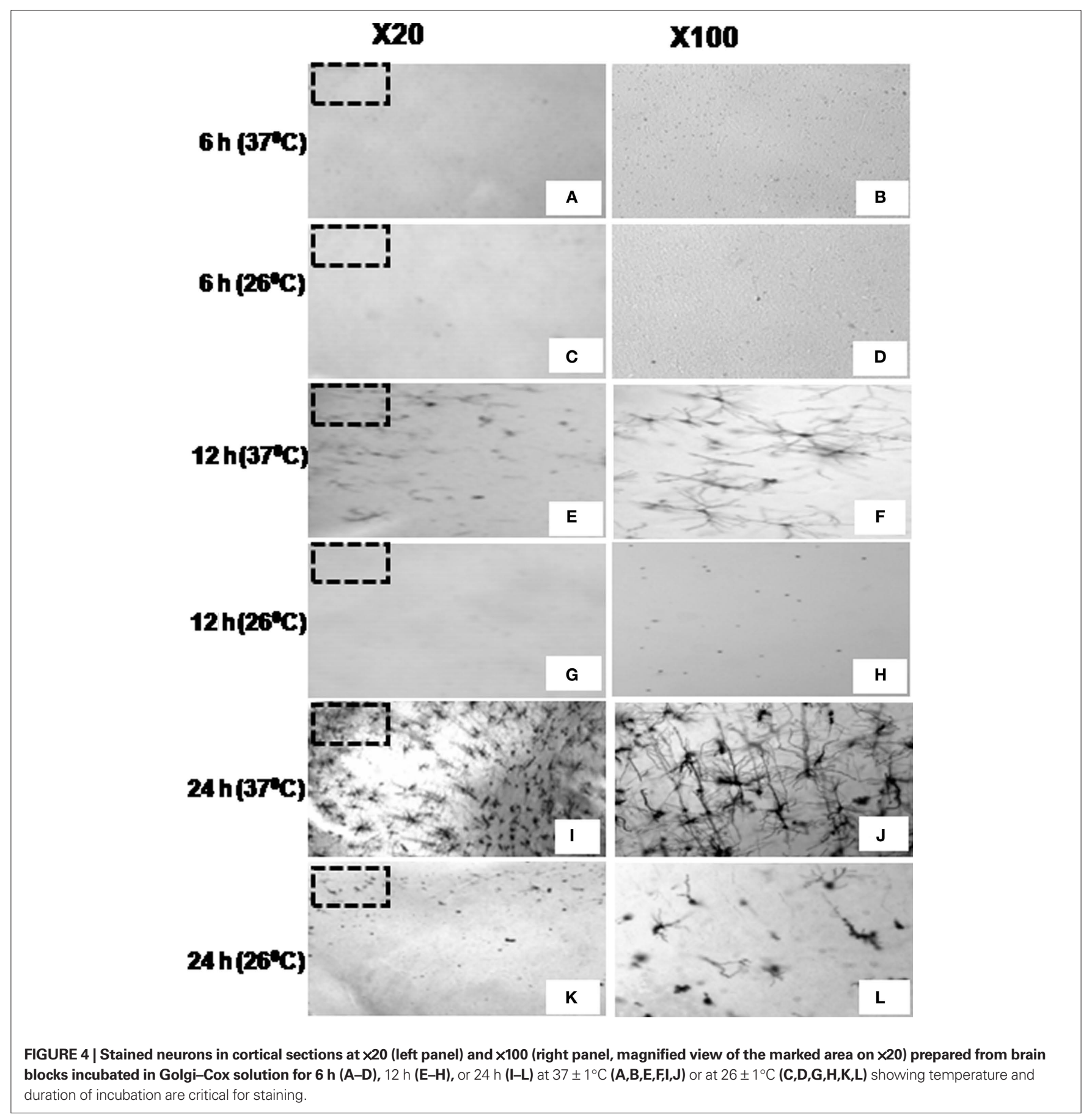

In contrast, the brain tissue blocks kept at $26 \pm 1{ }^{\circ} \mathrm{C}$ showed none or negligible staining after $12 \mathrm{~h}$ of incubation. However, after $24 \mathrm{~h}$ incubation at $26 \pm 1^{\circ} \mathrm{C}$, inconsistent between experiments and incomplete staining of a few neurons could be seen occasionally, discretely spread mostly in the cortical regions of the sections; insignificant number of partially stained neurons could be seen in the sub-cortical region (Figures 4-6). Qualitative comparison between control and experimental sections are shown in Tables 1 and 2. Quantitative analysis of number of neurons stained in different brain regions under various conditions has been shown in
Figure 8. Stereoscopic 3-D view of a neuron with its morphology and projections are shown in Figure 7, which may be conveniently used for further analysis.

Neither SDS nor Triton X-100 in the incubating medium improved the staining quality. The staining quality was comparable when the tissues were incubated at higher $\left(37 \pm 1^{\circ} \mathrm{C}\right)$ or lower $\left(26 \pm 1{ }^{\circ} \mathrm{C}\right)$ temperature as described above, irrespective of whether they were incubated in medium containing SDS or Triton X-100 (Table 1). Similarly, perfusion of the brain with PBS was also of little consequences and gave comparable results when 
incubated at the higher $\left(37 \pm 1^{\circ} \mathrm{C}\right)$ or lower $\left(26 \pm 1^{\circ} \mathrm{C}\right)$ temperature. These observations suggested that the improvement of staining was primarily due to the increased temperature of the tissue incubation medium.

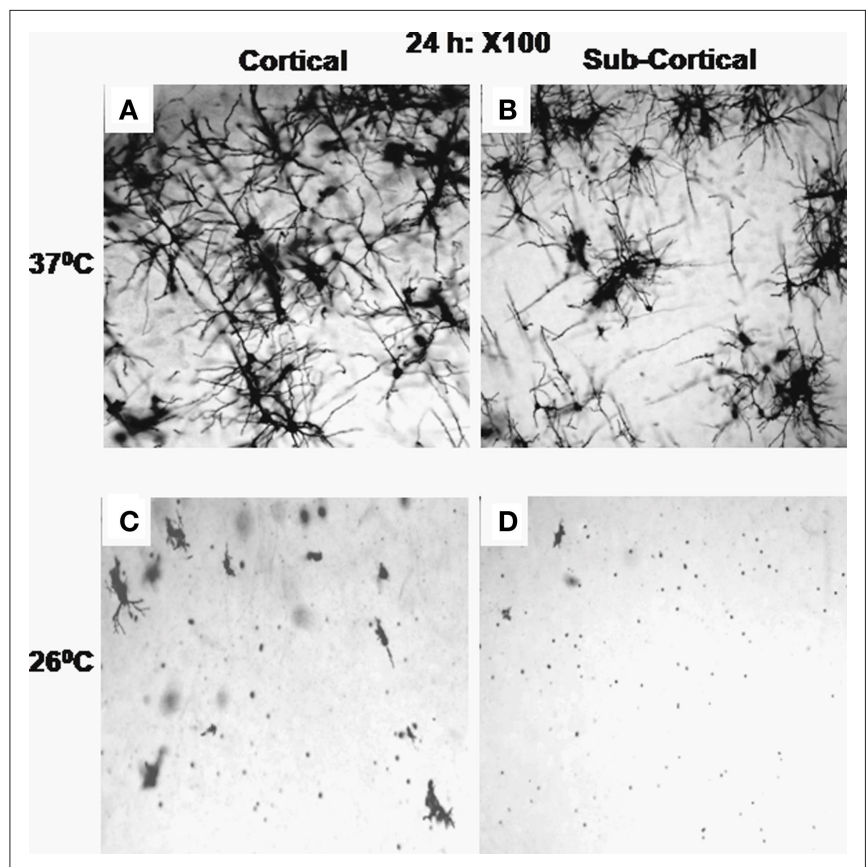

FIGURE 5 | Stained neurons $(x 100)$ in sections through cortical ( $A$ and $C)$ and sub-cortical (B and $\mathbf{D}$ ) areas after incubation of the brain blocks for $24 \mathrm{~h}$ at $37 \pm 1{ }^{\circ} \mathrm{C}(\mathbf{A}, \mathbf{B})$ and at $26 \pm 1{ }^{\circ} \mathrm{C}(\mathbf{C}, \mathbf{D})$ are shown. All the sections showed completely filled neurons at the end of $24 \mathrm{~h}$ incubation at $37 \pm 1^{\circ} \mathrm{C}$; however, very few neurons can be seen after incubation at $26 \pm 1^{\circ} \mathrm{C}$.

\section{DISCUSSION}

Golgi-Cox stain is one of the powerful techniques to study the neuronal morphology in brain sections (Ramon y Cajal, 1909). However, its major drawbacks are it is much time consuming to

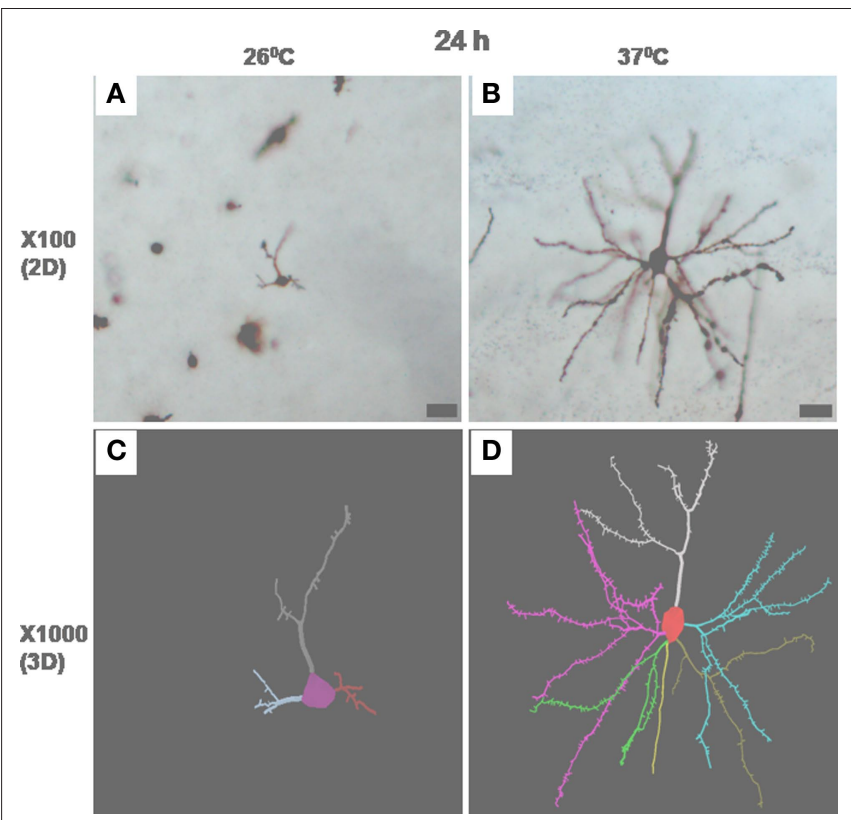

FIGURE 7 | Photomicrographs in one focal plane at $\times 100$ of stained neurons incubated at $26 \pm 1^{\circ} \mathbf{C}$ (A) and $37 \pm 1^{\circ} \mathrm{C}$ (B) for $24 \mathrm{~h}$ are shown. Several such traces taken in different planes have been reconstructed automatically by Neurolucida 9 and Neurolucida Explorer 9 and are shown in (C) and (D) as 3-D solid images. Magnified view of neuron in (A) and (B) are shown in (C) and (D), respectively. Scale bar $=25 \mu \mathrm{m}$.

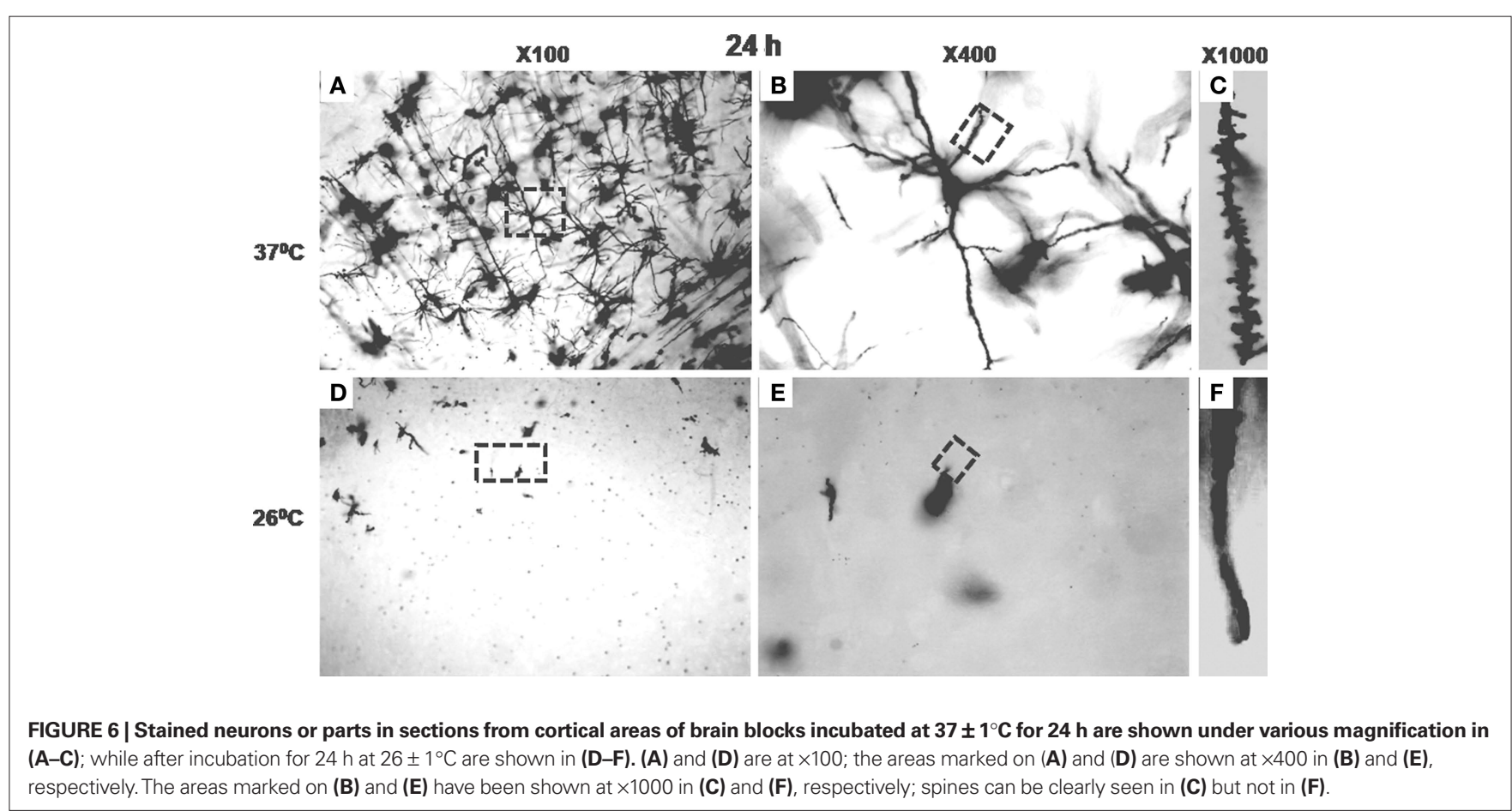


Table 2 | Effects of varying duration and temperature of incubation of the brain tissues on impregnation of Golgi-Cox stain into the neurons.

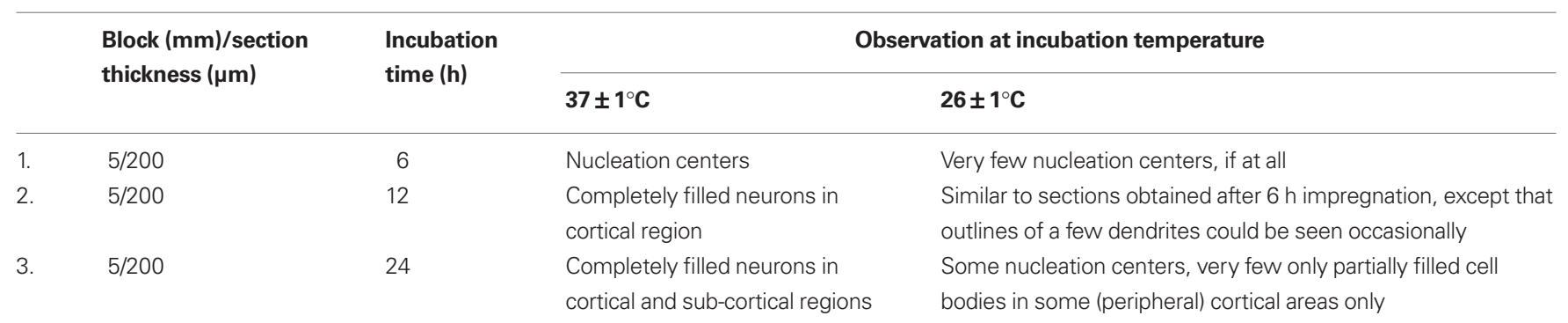

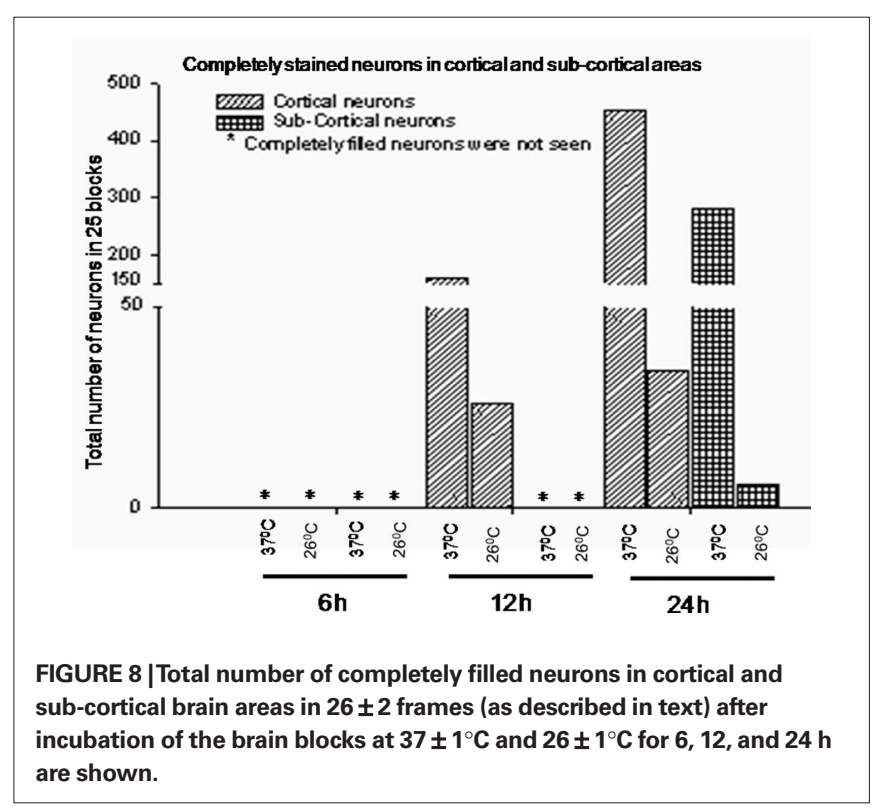

get the results, taking several weeks to more than a month; the results are not uniform, inconsistent and prone to high failure rates (Globus and Scheibel, 1966; Zhang et al., 2003; Friedland et al., 2006). In this study we incubated the brain tissues in classical Golgi-Cox solution at different temperatures and observed that incubation of the tissues at normal body temperature $37 \pm 1^{\circ} \mathrm{C}$ overcame those drawbacks. The effects due to the presence of blood and its constituents or due to perfusion with PBS were ruled out by using the brain taken out with or without perfusion with PBS. Similarly, to rule out the effect of membrane damage the brain tissues were incubated at various temperatures in medium with or without SDS and Triton-X 100 and the results were comparable. Thus, the findings suggest that the only factor to reduce the time for the stain to impregnate into the neurons was the incubation temperature at $37 \pm 1^{\circ} \mathrm{C}$.

Incubating brain blocks in the Golgi-Cox solution at $37^{\circ} \mathrm{C}$ dramatically reduced the time required to achieve complete and uniform staining of neurons. Sections obtained from contralateral blocks of the same brain kept in Golgi-Cox solution at $26^{\circ} \mathrm{C}$ were used as control. While excellent staining was achieved within $24 \mathrm{~h}$ in blocks incubated at $37^{\circ} \mathrm{C}$, very few completely stained neurons could be seen in homotopic areas in blocks kept at room temperature $\left(26 \pm 1^{\circ} \mathrm{C}\right)$. Since perfusion of the brain with PBS, and incubation of the tissues in medium containing SDS or Triton-
X100 produced comparable results when incubated at the same temperature, neuronal membrane damage causing influx of the stain may be ruled out. A possible rationale for such efficient staining is likely to be due to faster movement of the metallic molecules present in the Golgi-Cox stain solution at the higher incubation temperature. At higher temperature the rate of movement and kinetic energy of the metallic ions in the Golgi-Cox stain solution would facilitate to increase staining in reduced time. Variations in incubating temperature have been tried earlier but those did not yield better results. Earlier studies used various temperatures in the form of heat (Berbel, 1986; Angulo et al., 1994), microwave (Armstrong and Parker, 1986; Marani et al., 1987; Zhang et al., 2003), etc; however, temperature around $37^{\circ} \mathrm{C}$ for shorter time as that of in this study was not tested. Although a critical temperature $\left(37^{\circ} \mathrm{C}\right)$ improved staining, we cannot comment from this study what specific role the temperature might be playing in this process. It may be noted that the body fluids are composed of a large number of metallic and non-metallic ions, which exchange through the cellular membranes. Also, the body temperature in the homeotherms is set at a unique (magic) number close to $37^{\circ} \mathrm{C}$. Whether optimum ion transport through biological membrane has any bearing on evolutionary and physiological significance with the set temperature for thermoregulation in warm blooded animals is an open question.

Several methodological modifications of Golgi-Cox staining process have been attempted in the past, e.g., varying duration of incubation of the tissues in the Golgi solution and multiple impregnations (Millhouse, 1969), changes in $\mathrm{pH}$ of chromatin solutions (Bertram and Ihrig, 1957; Gonzalez-Burgos et al., 1992; Angulo et al., 1994), vacuum immersion of the tissues (Friedland et al., 2006), use of single sections for staining (Landas and Phillips, 1982; Gabbott and Somogyi, 1984), use of microwave energy (Armstrong and Parker, 1986; Marani et al., 1987; Zhang et al., 2003), and changes in temperature (Berbel, 1986; Angulo et al., 1994). Instead of blocks, use of individual sections (Landas and Phillips, 1982; Gabbott and Somogyi, 1984) are tedious and suffer from additional drawback that neurons stained in one section can not be followed in the next section as they may remain unimpregnated. In other methods (Table 3), the earliest complete staining of blocks could be obtained after at least 5 days unlike within $24 \mathrm{~h}$ in this study. Although in one study using solution (not Golgi-Cox) at $60^{\circ} \mathrm{C}$, staining within $24 \mathrm{~h}$ has been reported (Marani et al., 1987) with some other shortcomings though, since, it was not physiological temperature, it has more chance to alter architecture of neurons after staining. In all those methods up to $3 \mathrm{~mm}$ thick brain blocks were incubated in the staining solution, where as in our study we 
Table 3 | Comparison of impregnation of Golgi stain into the neurons under various conditions used by different authors.

\begin{tabular}{|c|c|c|c|c|c|c|}
\hline Method and author & Animals & $\begin{array}{l}\text { Incubation } \\
\text { period }\end{array}$ & $\begin{array}{l}\text { Tissue } \\
\text { block }(\mathrm{mm})\end{array}$ & $\begin{array}{l}\text { Section } \\
\text { slice }(\mu \mathrm{m})\end{array}$ & $\begin{array}{l}\text { Incubation } \\
\text { temperature }\left({ }^{\circ} \mathrm{C}\right)\end{array}$ & $\begin{array}{l}\text { Results/comments (by } \\
\text { authors) }\end{array}$ \\
\hline 1. Golgi-Cox (Rutledge et al., 1969) & Adult cats & 40-80 days & 5 & $100-125$ & RT & SN \\
\hline 3. Rio-Hortega (Marani et al., 1987) & Adult rats & 24 hours & 3 & $100-120$ & 60 & SN/microwave energy \\
\hline $\begin{array}{l}\text { 4. Golgi-Kopsch (Armstrong and } \\
\text { Parker, 1986) }\end{array}$ & AHB & $3-5$ days & 4 & $100-150$ & 55 & SN/microwave energy \\
\hline 6. Golgi-aldehyde (Berbel, 1986) & Old rats & 10-60 days & $0.5-1.5$ & 150 & 4 & $\begin{array}{l}\text { SN/reduces the formation of } \\
\text { precipitation and improves } \\
\text { staining }\end{array}$ \\
\hline
\end{tabular}

$A H B$, adult human being; RT, room temperature as mentioned by the authors; $S N$, stained neurons seen.

have used $5 \mathrm{~mm}$ thick blocks. Further, in most of those modified methods $80-150 \mu \mathrm{m}$ sections were studied under microscope. However, in our study we could use $200 \mu \mathrm{m}$ or thicker sections, which allow successfully following the extent of projections of stained neurons to increased depth. Thus, our method is significantly more advantageous for tracing neuronal projections and to study their synaptic connections for longer depth in 3-D. These properties and advantages could be used to study the connections between neurons located in areas which have been physiologically identified, e.g., in sleep, wake, and REM sleep modulation.

The results obtained in this study were reproducible and were not seen in the controls. Further, the findings were independent of tissue, animal, and area of the brain tissue being stained; hence, they cannot be due to non-specific artifacts. Another possibility of faster staining of neurons could be due to longitudinal sectioning of the brain tissue. However, such argument cannot be supported by the observation that the cortical neurons were stained first than the sub-cortical neurons; this study does not allow us to comment on this aspect.

\section{REFERENCES}

Angulo, A., Merchan, J. A., and Molina, M. (1994). Golgi-Colonnier method: correlation of the degree of chromium reduction and $\mathrm{pH}$ change with quality of staining. J. Histochem. Cytochem. 42, 393-403.

Armstrong, E., and Parker, B. (1986).A new Golgi method for adult human brains. J. Neurosci. Methods 17, 247-254.

Berbel, P. J. (1986). Chromation at low temperatures improves impregnation of neurons in Golgi-aldehyde methods. J. Neurosci. Methods 17, 255-259.

Bertram, E. G., and Ihrig, H. K. (1957). Improvement of the Golgi method by $\mathrm{pH}$ control. Stain Technol. 32, 87-94.
Buell,S.J. (1982). Golgi-Cox and rapid golgi methods as applied to autopsied human brain tissue: widely disparate results. J. Neuropathol. Exp. Neurol. 41, 500-507.

Friedland, D. R., Los, J. G., and Ryugo, D. K. (2006). A modified Golgi staining protocol for use in the human brain stem and cerebellum. J. Neurosci. Methods 150, 90-95.

Gabbott, P.L., and Somogyi, J. (1984). The "single" section Golgi-impregnation procedure: methodological description. J. Neurosci. Methods 11, 221-230.

Gibb, R., and Kolb, B. (1998). A method for vibratome sectioning of Golgi-Cox stained whole rat brain. J. Neurosci. Methods 79, 1-4.

Glaser, E. M., and Van der Loos, H. (1981). Analysis of thick brain sections by

\section{CONCLUSION}

Incubating the brain tissue around body temperature at $37 \pm 1^{\circ} \mathrm{C}$ improved Golgi-Cox staining efficiency and reduced the time of staining, which were the primary drawbacks of using Golgi-Cox method. This modified protocol should allow the researchers to significantly increase their turnover in studying the anatomical connections between neurons located in different anatomical regions and whose functions might have been known. It will facilitate studying arborizations as well as spine counting on neurons, including whose anatomical connections and physiological identifications, e.g., wake, sleep, REM sleep, memory, etc has been established. Additional significant advantage of this modified method lies in the fact that it does not require any specialized equipment or chemicals.

\section{ACKNOWLEDGMENTS}

Funding from Indian agencies viz. Council of Scientific and Industrial Research, Department of Science and Technology and UGC-Capacity Build Up are acknowledged.

obverse-reverse computer microscopy: application of a new, high clarity Golgi-Nissl stain. J. Neurosci. Methods 4, 117-125.

Globus, A., and Scheibel, A. B. (1966). Loss of dendrite spines as an index of pre-synaptic terminal patterns. Nature 212, 463-465.

Golgi, C. (1873). Sulla struttura della sostanza grigia dell cervello. Gaz. Med. Lomb. 33, 244-246.

Gonzalez-Burgos, I., Tapia-Arizmendi, G., and Feria-Velasco, A. (1992). Golgi method without osmium tetroxide for the study of the central nervous system. Biotech. Histochem. 67, 288-296.

Landas, S., and Phillips, M.I.(1982).Staining of human and rat brain Vibratome sections by a new Golgi method. J. Neurosci. Methods 5, 147-151.

Marani, E., Guldemond, J. M., Adriolo, P. J., Boon, M. E., and Kok, L. P. (1987). The microwave Rio-Hortega technique: a 24 hour method. Histochem. J. 19, 658-664.

Mazzarello, P. (1999). Camillo Golgi's scientific biography. J. Hist. Neurosci. 8, 121-131.

Millhouse, O. E. (1969). A Golgi study of the desending medial forebrain bundle. Brain Res. 15, 341-363.

Pasternak, J. F., and Woolsey, T. A. (1975). On the "selectivity" of the GolgiCox method. J. Comp. Neurol. 160, 307-312.

Ramon y Cajal, R. (1909). Histologie du System Nerveux de I'Homme et des 
Veertebres. Madrid: Instituto Ramon y Cajal, 774-838.

Rutledge, L. T., Duncan, J., and Beatty, N. (1969). A study of pyramidal cell axon collaterals in intact and partially isolated adult cerebral cortex. Brain Res. 16, 15-22.

Scheibel, A. B., and Tomiyasu, U. (1978). Dendritic sprouting in Alzheimer's presenile dementia. Exp. Neurol. 60, 1-8.
Zhang, H., Weng, S. J., and Hutsler, J. J. (2003). Does microwaving enhance the Golgi methods? A quantitative analysis of disparate staining patterns in the cerebral cortex. J. Neurosci. Methods 124, 145-155.

Conflict of Interest Statement: The authors declare that the research was conducted in the absence of any commercial or financial relationships that could be construed as a potential conflict of interest.

Received:27July2010; accepted: 14December 2010; published online: 28 December 2010. Citation: Ranjan A and Mallick BN (2010) A modified method for consistent and reliable Golgi-Cox staining in significantly reduced time. Front. Neur. 1:157. doi: 10.3389/fneur.2010.00157
This article was submitted to Frontiers in Sleep and Chronobiology, a specialty of Frontiers in Neurology.

Copyright ( 2010 Ranjan and Mallick. This is an open-access article subject to an exclusive license agreement between the authors and the Frontiers Research Foundation, which permits unrestricted use, distribution, and reproduction in any medium, provided the original authors and source are credited. 